\title{
LOW-POTASSIUM DEXTRAN PRESERVATION SOLUTION IMPROVES LUNG FUNCTION AFTER HUMAN LUNG TRANSPLANTATION
}

Stefan Fischer, MD, ${ }^{\text {a }}$ Andrea Matte-Martyn, BSc, RT, ${ }^{\text {a }}$ Marc de Perrot, MD, ${ }^{\text {a }}$ Thomas K. Waddell, MD, PhD, FRCSC, ${ }^{a}$ Yasuo Sekine, MD, PhD, ${ }^{a}$ Michael Hutcheon, MD, FRCPC, ${ }^{b}$ and Shaf Keshavjee, MD, MSc, FRCSC, FACS, ${ }^{a}$

Toronto, Ontario, Canada

\begin{abstract}
Lung transplantation is an established therapeutic modality for end-stage lung diseases. In the immediate post-transplantation period, life-threatening graft dysfunction occurs in up to $20 \%$ of patients, a percentage that has remained largely unchanged for several years. As reported by the International Society for Heart and Lung Transplantation (ISHLT) in 1999, the 5-year survival after lung transplantation is approximately $50 \%$. The most important factor adversely affecting long-term survival after lung transplantation is bronchiolitis obliterans syndrome, which is generally considered to be a complex end result of a chronic rejection process. However, about $15 \%$ of patients die within the first 3 months after lung transplantation
\end{abstract}

From the Toronto Lung Transplant Program, Division of Thoracic Surgery, Departments of Surgery ${ }^{\mathrm{a}}$ and Respirology, ${ }^{\mathrm{b}}$ Toronto General Hospital, University Health Network, University of Toronto, Toronto, Ontario, Canada.

Received for publication March 29, 2000; accepted for publication June 28, 2000.

Address for reprints: S. Keshavjee, MD, Director, Toronto Lung Transplant Program, Division of Thoracic Surgery, Toronto General Hospital, 200 Elizabeth St, EN 10-224, Toronto, Ontario, Canada M5G 2C4 (E-mail: shaf.keshavjee@uhn.on.ca).

J Thorac Cardiovasc Surg 2001;120:594-6

Copyright (C) 2001 by The American Association for Thoracic Surgery

$0022-5223 / 2001 \$ 35.00+0 \quad \mathbf{1 2 / 5 4 / 1 0 9 7 0 3}$

doi:10.1067/mtc.2001.109703 of severe organ dysfunction related to ischemia/reperfusion injury, acute rejection, and infection. ${ }^{1}$

In clinical practice, acceptable graft storage times are limited to around 6 hours. A recent report reaffirmed the occurrence of diminishing graft function after periods of storage in excess of 4 hours. ${ }^{2}$ The strategy used for preservation of lung grafts is important and has been the subject of much experimental research over the past 10 years. It has been shown that inflated lungs are able to maintain aerobic metabolism during the period of cold ischemia. ${ }^{3}$ In contrast, solid organs such as the liver and pancreas undergo anaerobic metabolism during storage. Despite this, those organs can be stored safely for up to 24 hours with current techniques, reflecting perhaps a better understanding of the behavior of those organs during ischemia and also their inherently more robust anatomic characteristics.

Much experimental work has been directed toward improving the quality of lung preservation, in particular the evaluation of low-potassium dextran solution (LPD), University of Wisconsin solution, Euro-Collins solution (EC), and Wallwork blood-based solutions, each one in conjunction with a variety of pharmacologic adjuncts. Although strong evidence exists supporting the use of alternatives to the commonly used EC, the slow adoption of such knowledge into clinical practice is somewhat alarming, as highlighted in a recent survey of current clinical practice. ${ }^{4}$

Initial results from experimental lung transplantation in the development and modification of LPD at our institution indi- 
cated that dextran 40 and low potassium concentration both contribute significantly to uniformly excellent 12-hour lung preservation and post-transplantation function seen with LPD compared with EC. ${ }^{5}$ We have subsequently demonstrated that standard LPD is less cytotoxic than EC, that LPD enables higher levels of metabolic activity in recovering isolated alveolar type II epithelial cells, and that dextran does not act as a superoxide radical scavenging mechanism. ${ }^{6}$ These and other results by various other investigators in experimental lung transplantation using LPD confirm the potential for improved human lung preservation.

Encouraged by our own observations and those of other groups, the Toronto Lung Transplant Program has now adopted LPD preservation solution into clinical practice after approval was obtained for the use of LPD in clinical lung transplantation in April 1998. This article reports our initial experience with the use of LPD in comparison with EC in 94 lung clinical lung transplant procedures.

Methods and results. Data were prospectively recorded for 108 consecutive lung transplant procedures performed between May 1996 and November 1999. All patients who received single lung transplants were removed from this analysis $(n=13)$. This was done to avoid the potential confounding influence on overall oxygenation of the remaining native lung in patients after single lung transplantation. Unequivocal evaluation of transplanted lung function after ischemic preservation and transplantation is possible only in patients who receive either heart-lung or bilateral lung transplants. One patient with bronchiolitis obliterans, who received a re-transplant, was also excluded from the study. The outcome of 46 procedures after graft preservation with LPD (Perfadex, Vitrolife, Uppsala, Sweden) was compared with the results after transplantation for 48 procedures performed with EC (Baxter Healthcare Corp, Pharmacy Division, Deerfield, Ill) for graft preservation. Alprostadil (prostaglandin $\mathrm{E}_{1}$, Prostin VR; Upjohn, Don Mills, Ontario, Canada) was used before lung flush and in the flush solution $(0.5 \mathrm{mg}$ each). Lungs were flushed with $4 \mathrm{~L}$ of preservation solution and stored in preservation solution in an inflated state. Since 1996, inhaled nitric oxide was used as indicated for severe graft dysfunction. From December 1997 on, all patients in our program were enrolled in an ongoing double-blind randomized controlled trial on the use of inhaled nitric oxide after transplantation; therefore, half received nitric oxide and half received placebo.

For the purpose of this study, the primary end point was initial post-transplantation graft function as assessed by arterial oxygen tension/inspired oxygen fraction $\left(\mathrm{PaO}_{2} / \mathrm{FIO}_{2}\right)$ ratio on arrival in the intensive care unit. Secondary end points included APACHE (Acute Physiology and Chronic Health Evaluation) score on arrival in the intensive care unit and 30day survival. Age, sex, indication for transplant, type of transplant (bilateral or heart-lung transplants), and total graft ischemic times were also compared between these two groups. The results were analyzed by analysis of variance (continuous data) or the Fisher exact test (categoric data) and are expressed as the mean \pm standard deviation.

Although this was not a randomized trial, the two groups were reasonably evenly matched for important risk factors,
Table I. Demographic patient data in group

\begin{tabular}{lcc} 
comparison & & \\
\hline & LPD group & EC group \\
\hline Age (y) & 44 & \\
$\quad$ Mean & $12-68$ & $15-67$ \\
$\quad$ Range & & \\
Sex (n) & 30 & 21 \\
$\quad$ Female patients & 24 & 33 \\
Male patients & & \\
Type of transplant (n) & 7 & 6 \\
Single lung transplant & 45 & 47 \\
Bilateral lung transplant & 2 & 1 \\
Heart-lung transplant & & \\
Reason for transplant (n) & 20 & 15 \\
$\quad$ Emphysema & 13 & 16 \\
Cystic fibrosis & 10 & 8 \\
Idiopathic pulmonary fibrosis & 5 & 6 \\
Primary pulmonary fibrosis & 1 & 1 \\
Sarcoidosis & 3 & 2 \\
Bronchiectasis & 1 & 1 \\
Lymphangioleiomyomatosis & 1 & 5 \\
Idiopathic bronchiolitis obliterans & & \\
\hline
\end{tabular}

such as patient sex and age, type of transplant, and reason for transplant (Table I).

Lung function as assessed by $\mathrm{PaO}_{2} / \mathrm{FIO}_{2}$ was significantly better in the LPD group $(370 \pm 133 \mathrm{~mm} \mathrm{Hg})$ than in the EC group $(310 \pm 134 \mathrm{~mm} \mathrm{Hg} ; P=.017)$, despite significantly longer total graft ischemic times in the LPD group (348 \pm 69 minutes vs $298 \pm 92$ minutes; $P=.024$ ). Clearly, a very important and clinically relevant end point is the development of severe life-threatening graft dysfunction. All patients were therefore categorized according to their $\mathrm{PaO}_{2} / \mathrm{FIO}_{2}$ ratios. A $\mathrm{PaO}_{2} / \mathrm{FIO}_{2}$ ratio of less than 150 clearly represents severe graft dysfunction after lung transplantation. In the EC group, 10 of 48 patients $(20.8 \%)$ had a $\mathrm{PaO}_{2} / \mathrm{FIO}_{2}$ ratio less than 150 , whereas in the LPD group only 5 of 46 patients $(10.9 \%)$ had a $\mathrm{PaO}_{2} / \mathrm{FIO}_{2}$ ratio below 150 . Therefore, significantly more patients in the EC group demonstrated what would be clearly recognized as life-threatening graft dysfunction after transplantation than in the LPD group $(P=.044)$. There was a trend toward an improved APACHE score in the LPD group $(\mathrm{LPD}=18.1 \pm 5.3$ vs $\mathrm{EC}=24.6 \pm 7.8 ; P=.08)$ and also a trend toward a lower 30-day mortality $(P=.082)$ in the LPD group (LPD, $\mathrm{n}=3 / 46,6.5 \%$; $\mathrm{EC}, \mathrm{n}=5 / 48,10.4 \%$ ).

Comment. Graft preservation with LPD demonstrated improved lung function in the early phase after clinical lung transplantation compared with EC, despite significantly longer ischemic times. This superior outcome with LPD is consistent with evidence from experimental lung transplant studies that LPD is superior to EC for lung preservation. ${ }^{5}$ Experimental data suggest longer safe ischemic times are possible with LPD than EC. To our knowledge, this is the first report that supports these findings in clinical lung transplantation as well. The initial choice of EC as a lung preservation solution was based on the experimental evidence available at 
the conception of clinical transplantation in the early 1980s. Although we acknowledge that a randomized study might provide more compelling data, we did not believe that such a study could be ethically justified given the wealth of data now available demonstrating the clear benefit of LPD in experimental studies. All data in this study were collected prospectively in a mature lung transplant program without a learning curve on equally matched study groups; these features indicate the strengths of our study. Our surgical judgment is that LPD provides better lung preservation than EC in clinical lung transplantation, and we are very satisfied with the switch to LPD in clinical practice. In future studies we hope to provide long-term follow-up results on the use of LPD in clinical lung transplantation. These data will ideally determine whether this improved early graft function is translated into decreased long-term graft dysfunction in transplanted lungs.

\section{REFERENCES}

1. Hosenpud JD, Bennett LE, Keck BM, Fiol B, Boucek MM, Novick RJ. The Registry of the International Society for Heart and Lung Transplantation: sixteenth official report-1999. J Heart Lung Transplant 1999;18:611-26.

2. Bund M, Struber M, Heine J, Jaeger K, Wahlers T, Haverich A, et al. Effect of lung allograft ischaemia duration on postreperfusion graft function and postoperative course. Thorac Cardiovasc Surg 1998;46:93-6.

3. Date H, Matsumura A, Manchester JK, Cooper JM, Lowry OH, Cooper JD. Changes in alveolar oxygen and carbon dioxide concentration and oxygen consumption during lung preservation: the maintenance of aerobic metabolism during lung preservation. $\mathrm{J}$ Thorac Cardiovasc Surg 1993;105:492-501.

4. Hopkinson DN, Bhabra MS, Hooper TL. Pulmonary graft preservation: a worldwide survey of current clinical practice. J Heart Lung Transplant 1998;17:525-31.

5. Keshavjee SH, Yamazaki F, Cardoso PF, McRitchie DI, Patterson GA, Cooper JD. A method for safe twelve-hour pulmonary preservation. J Thorac Cardiovasc Surg 1989;98:529-34.

6. Maccherini M, Keshavjee SH, Slutsky AS, Patterson GA, Edelson JD. The effect of low-potassium-dextran versus EuroCollins solution for preservation of isolated type II pneumocytes. Transplantation 1991;52:621-6. 